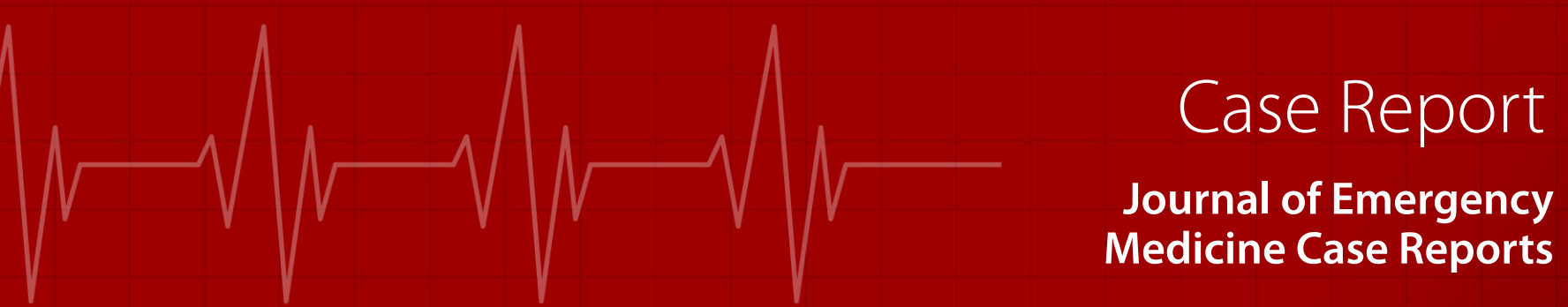

\title{
Is Computed Tomography the Gold Standard in Aortic Dissection?
}

Sefa TATAR', Abdullah içLi'1', Hakan AKILLI', Niyazi GÖRMüş², Ahmet Lütfü SERTDEMiR

'Necmettin Erbakan University, Meram Medical Faculty, Department of Cardiology, Konya, Turkey

${ }^{2}$ Necmettin Erbakan University, Meram Medical Faculty, Department of Cardiovascular Surgery, Konya, Turkey

\section{Abstract}

Introduction: Aortic dissection is a disease with high mortality, which is characterized by a tear in the aortic wall. Thanks to early diagnosis and treatment, patients' survival rates are high. Chest pain is the most common symptom. Imaging methods help in diagnosis. Its treatment is surgery.

Case Report: A 47-year-old male patient was admitted to the emergency department with chest pain. The diagnosis of aortic dissection in computed tomography was evaluated as motion artifact and valve motion, and he was asked to be discharged from the emergency service after his diagnosis was missed. However, transesophageal echocardiography was performed because of the patient's clinical symptom and echocardiographic findings supported the aortic dissection. When a dissection flap was seen in transesophageal echocardiography, the patient was transferred to surgery. In surgery, a dacron graft was placed in the patient's aorta and a prosthetic valve was placed on the aortic valve, and left main coronary repair and right coronary is bypass were performed. The patient was discharged without any problem.

Conclusion: Aortic dissection is a clinical diagnosis, it is a disease with high mortality. Imaging methods are helpful in diagnosis, but the fact that imaging methods rule out dissection does not always rule out the disease. The important thing is to suspect the disease and to consider the patient's current clinical symptoms and signs.

Keywords: Aortic dissection, computed tomography, transesophageal echocardiography, surgery.

\section{Introduction}

Aortic dissection is the filling of blood into the aortic wall as a result of a tear in the aortic intima. Aortic dissection is one of the real emergencies due to high mortality. Therefore, diagnosis and treatment should not be delayed. It is frequently seen in men between the ages of 40-70. The most common cause of aortic dissection is uncontrolled hypertension ${ }^{1}$. Autoimmune diseases, bicuspid aorta, aortic aneurysm history, chronic constipation, pregnancy, congenital anomalies, blunt traumas, connective tissue diseases are among other etiological reasons ${ }^{2-3}$. The typical clinical picture of aortic dissection is very severe chest pain in the form of tearing or rupture starting from the anterior chest wall and other clinical symptoms that increase with the progress of the dissection. Clinical findings occur as a result of the effects of branches separated from the aorta. While neurological symptoms such as syncope and stroke are prominent in proximal aortic involvement, mesenteric ischemia, lower extremity sensory and motor losses, and renal failure may occur in distal aortic involvement ${ }^{4}$.

\section{Case report}

A 47-year-old male patient, who had no known history of systemic or coronary disease and had a history of smoking one pack per day for 30 years, was examined in another center 1 week ago due to chest pain and syncope, and no cardiac pathology was found. Computed tomographic (CT) angiography was performed with a preliminary diagnosis of aortic dissection, but it was evaluated by radiology as motion artifact and valve motion, and aortic dissection was not considered (Figure 1a). During his admission to our center for control purposes, the patient had atypical chest pain, hemodynamically stable, and there was no pathological feature on electrocardiography. In echocardiography, the ejection fraction was $60 \%$, there was no wall motion disorder, but the patient had a $0.5 \mathrm{~cm}$ pericardial effusion in the posterior and lateral wall. Advanced aortic insufficiency was detected without an organic pathology in the aortic valve. The ascending aorta was not wide and measured $40 \mathrm{~mm}$ from its widest point. After the rupture of a fibrous band at the sinotubular junction and a suspicious dissection image, the patient underwent CT angiography again (Figure 1b). It was evaluated by the radiology 
as motion artifact and valve motion again and dissection was not considered. The patient was consulted with cardiovascular surgery, and the patient was asked to be discharged from the emergency department, since dissection was not considered as a result of tomography. However, due to the dissection image and high clinical suspicion in the echocardiography performed by the cardiology, the patient was performed transesophageal echocardiography (TEE) and a dissection image starting from the sinotubular junction was observed (Figure 1c). At the same time, advanced aortic regurgitation was detected that completely filled the left ventricular outflow tract (LVOT) (Figure 1d). In the operation performed on the patient, it was observed that the aortic wall was teared up to the tunica adventitia, the tear extended to the left main coronary and right coronary ostium, and extended to the pulmonary artery and limited itself by developing hematoma (Figure 2). A dacron graft was placed in the aorta, and then a prosthetic aortic valve was placed. The left main coronary ostium was repaired and the right coronary artery was bypassed saphenous (Figure 3). The patient, whose postoperative follow-up did not develop any problems, was discharged.

\section{Discussion}

Chest pain is the most common clinical presentation of aortic dissection. However, symptoms vary in some patients according to the involvement level of the aorta. In dissections involving the proximal part of the aorta, such as Type A dissection, the ostium of the coronary arteries may also be affected by this tear. Patients can sometimes present to the emergency department with the clinic of myocardial infarction with ST segment elevation, while in some patients, electrocardiographic changes have not yet occurred at an early stage, and the coro-
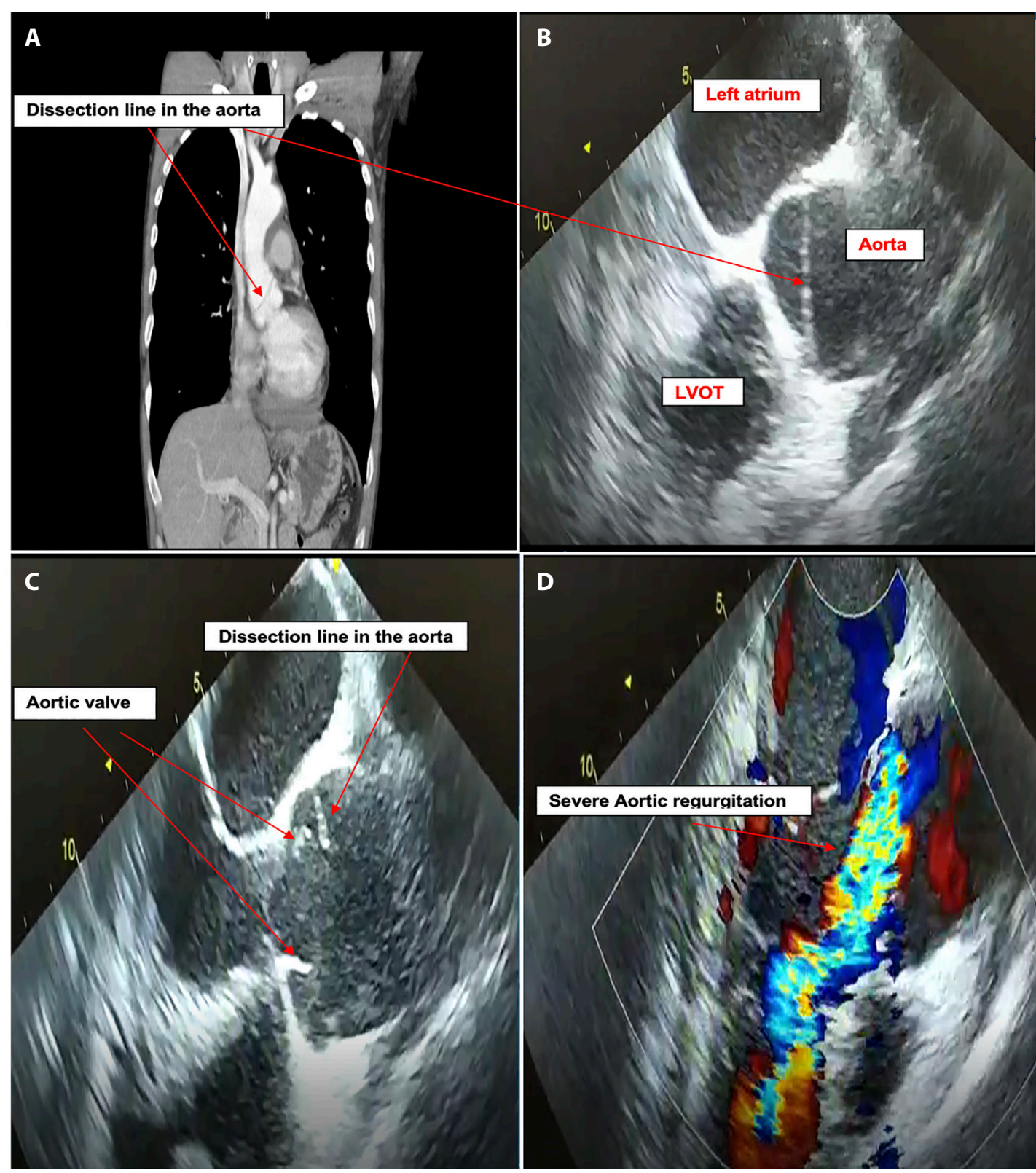

Figure 1: A; Dissection line is seen on tomography. B- C; Transesophageal echocardiography shows a dissection line. D; Transesophageal echocardiography shows severe aortic regurgitation. 


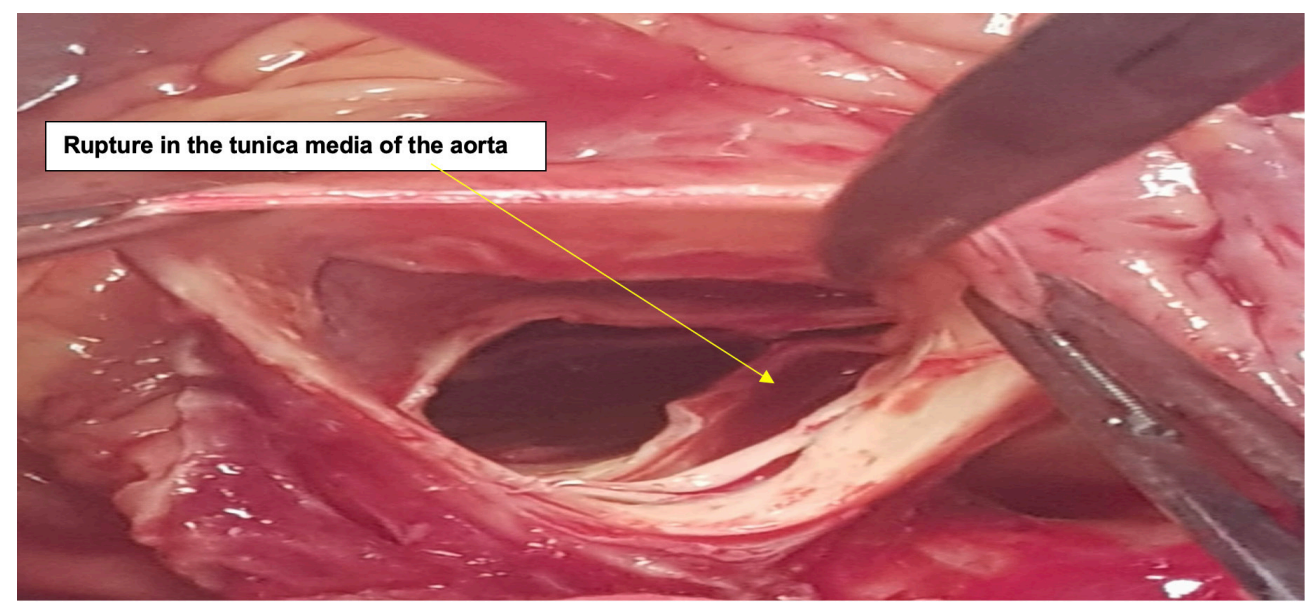

Figure 2: The tear in the aortic wall appears to extend to the tunica adventitia.

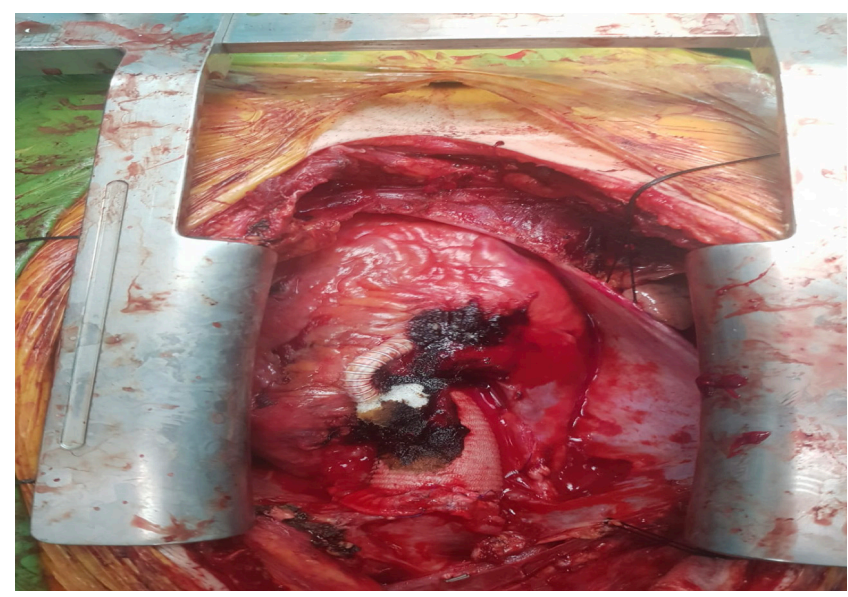

Figure 3: Repair of the coronary ostium

nary ostium may close with the advancement of the dissection line in the following hours. With the closure of the coronary ostia, mortality increases further. The right coronary artery is the most commonly involved coronary ostia, and patients may present with inferior myocardial infarction ${ }^{5}$. Routine coronary angiography in these patients is still controversial. In the studies performed, no significant difference was found between the patients who underwent preoperative coronary angiography and those who did not undergo mortality, length of stay and discharge ${ }^{6}$. Surgical techniques such as Bentall, David or Cabrol can be applied depending on the involvement of the aortic valve and the distance of the flap to the coronary ostium $^{7}$. Dissections starting from the aortic root are sometimes accompanied by aortic insufficiency. Aortic dissection should be kept in mind especially in patients who develop severe valve insufficiency without primary valve pathology. Aortography, magnetic resonance imaging (MRI), echocardiography and computed tomography can be used in the diagnosis of aortic dissection. However, considering the difficulties in the imaging technique, difficulties in transportation, and the clinical condition of the patient, MRI is not a practical method. Computed tomography is the most preferred diagnostic method because it is available in most hospitals, easy accessibility and fast results. Although computed tomography is accepted as the gold standard method for the diagnosis of dissection, it should be kept in mind that dissection diagnosis can be missed with tomography as in our case. Excluding the diagnosis of dissection by CT angiography in young patients with clinical symptoms, severe aortic regurgitation without primary valve pathology, and pericardial effusion should not exclude clinicians from this pre-diagnosis.

\section{Conclusion}

Aortic dissection is a clinical diagnosis, it is a disease with high mortality. Imaging methods are helpful in diagnosis, but the fact that imaging methods rule out dissection does not always rule out the disease. The important thing is to suspect the disease and to consider the patient's current clinical symptoms and signs.

\section{References}

1. Hagan PG, Nienaber CA, Isselbacher EM, Bruckman D, Karavite DJ, Russman PL. The International Registry of Acute Aortic Dissection (IRAD): New insights into an old disease. JAMA. 2000;283:897-903

2. Khan IA, Nair CK. Clinical, diagnosis, and management perspectives of aortic dissection. Chest. 2002;122:311-8.

3. Akgün FS, Turtay MG, Dişli OM, Oğuztürk H, Doğan M. Bacak ağrısıyla karakterize akut aort diseksiyonu. Genel Tıp Derg. 2011;21: 155-7

4-. Mumcu $S$, Akgün $M$, Örken DN. Nörolojik bozulma ile baş gösteren aort diseksiyonu olguları. Türk Nöroloji Dergisi. 2014; 20: 51-3

5. Ramanath VS, Eagle KA, Nienaber CA. The role of preoperative coronary angiography in the setting of type $A$ acute aortic dissection: Insights from the International Registry of Acute Aortic Dissection. Am Heart J. 2011;161(4):790- 796.

6. Wang ZG, Zhao W, Shen BT. Successful treatment of a case of acute myocardial infarction due to type A aortic dissection by coronary artery stenting: A case report. Exp Ther Med. 2015;10(2):759-762.

7. Kourliouros A, Soni M, Rasoli. Evolution and current applications of the Cabrol procedure and its modifications. Ann Thorac Surg. 2011;91(5):1636-41. 